\title{
Expression of hypoxia-inducible factor-1 alpha and associated proteins in pancreatic ductal adenocarcinoma and their impact on prognosis
}

\author{
HONG-CHENG SUN ${ }^{1}$, ZHENG-JUN QIU ${ }^{1}$, JUN LIU ${ }^{1}$, JING SUN ${ }^{1}$, TAO JIANG ${ }^{1}$, \\ KE-JIAN HUANG ${ }^{1}$, MIN YAO $^{2}$ and CHEN HUANG ${ }^{1}$ \\ ${ }^{1}$ Department of General Surgery, Affiliated First People's Hospital, Shanghai Jiao Tong University, \\ Shanghai 200080, P.R. China; ${ }^{2}$ Section of Gastroenterology, Boston University \\ School of Medicine and Boston Medical Center, Boston, MA 02118, USA
}

Received February 12, 2007; Accepted April 4, 2007

\begin{abstract}
The aim of this study was to assess the significance of expression of hypoxia-inducible factor- $1 \alpha$ $(\mathrm{HIF}-1 \alpha)$ and associated proteins in pancreatic ductal adenocarcinoma (PDA) and their impact on prognosis. Expression of HIF-1 $\alpha$, vascular endothelial growth factor (VEGF), glucose transporter-1 (Glut-1), survivin, CD34 and Ki-67 and apoptotic cells was demonstrated by immunohistochemistry or TUNEL in 58 PDAs and 20 normal pancreatic tissue samples. Our results show positivity of HIF- $1 \alpha$, VEGF, Glut-1 and survivin in $70.7 \%, 77.6 \%, 67.2 \%$ and $84.5 \%$ of the patients with PDA, respectively, which is significantly higher than in the normal counterparts. Expression of HIF- $1 \alpha$ correlated positively with VEGF and Glut-1 expression but not with survivin. Strong HIF-1 $\alpha$ expression associated with decreased apoptotic index and increased intratumoral microvessel density. Higher HIF-1 $\alpha$, VEGF and Glut-1 expression significantly associated with advanced tumor stage and lymph node metastasis. Patients with high HIF-1 $\alpha$, VEGF and Glut-1 expressing tumors had a poorer overall survival. Furthermore, Cox regression analysis showed that HIF- $1 \alpha$ is a prognostic marker of borderline significance while VEGF was important in predicting poor outcome. These results suggest that over-expression of HIF- $1 \alpha$ may play an important role in cancer progression through upregulation of VEGF and Glut-1 in PDA patients. HIF- $1 \alpha$ and VEGF are potential candidates for predicting survival.
\end{abstract}

Correspondence to: Dr Zheng-Jun Qiu, Department of General Surgery, Affiliated First People's Hospital, Shanghai Jiao Tong University, 85 Wujin Road, Shanghai 200080, P.R. China

E-mail: qiuwryb@online.sh.cn

Key words: pancreatic cancer, hypoxia-inducible factor-1 (HIF-1), vascular endothelial growth factor, angiogenesis, Glut-1, survivin, apoptosis, prognosis

\section{Introduction}

Pancreatic cancer, $90 \%$ of which is ductal adenocarcinoma, is considered to be one of the most aggressive human cancers. Although substantial improvements have been made in the surgical technique of pancreaticoduodenectomy, prognosis of pancreatic ductal adenocarcinoma (PDA) remains dismal. Hypovasculature, a main characteristic of PDA, is used in imaging diagnosis, hence fast proliferating pancreatic cancer tissues appear hypoxic, due to poor blood supply. However, malignant cells can undergo genetic and adaptive changes that allow them to survive during oxygen and nutrition deprivation.

Hypoxia-inducible factor-1 (HIF-1) is one of the key regulators under these conditions. HIF-1, a heterodimeric transcription factor, is composed of two basic-helix-loophelix (bHLH)-PAS subunits HIF- $1 \alpha$ and HIF-1ß. HIF- $1 \alpha$ is a unique oxygen-regulated component which determines HIF-1 activity. HIF-1 $\alpha$ accumulates when its proteolytic degradation by ubiquitin proteasome pathway (1) is inhibited and phosphatidylinositol 3'-kinase/Akt pathway is activated (2). HIF-1 $\alpha$ acts as a master regulator of numerous hypoxia-inducible genes related to tumor angiogenesis, cell proliferation or survival and glucose metabolism. Thus increased HIF-1 $\alpha$ expression could be associated with malignant potential and unfavorable patient prognosis. VEGF plays a central role in the tumor neo-angiogenesis which is a crucial step in tumor growth and progression. Glut-1 mediates cellular glucose uptake and thus facilitates anaerobic glycolysis, a prerequisite for cancer cell proliferation under hypoxic microenvironment. Survivin, a specific member of the apoptosis inhibitor protein family, is uniquely expressed in various kinds of human malignances but not in normal adult cells. Over-expression of survivin is associated with reduced cell apoptosis in many kinds of cancers including pancreatic cancer.

A complicated network of diverse genes and proteins contributes to tumor progression (3). It is therefore possible, that a combination of markers might be required to fully evaluate their significance for a given tumor type. Although high levels of HIF-1 $\alpha$ expression has been shown in many 
Table I. Summary of clinical and pathological characteristics.

\section{Characteristics}

$\begin{array}{lc}\text { Age (years) } & \\ \text { Median } & 62 \\ \text { Range } & 32-78 \\ \text { Gender } & \\ \text { Male } & 37 \\ \text { Female } & 21\end{array}$

$\begin{array}{lr}\text { TNM stage } & \\ \text { I } & 7 \\ \text { II } & 29 \\ \text { III } & 17 \\ \text { IV } & 5\end{array}$

Lymph node status

Negative 40

Positive 18

$\begin{array}{lr}\text { Margin status } & \\ \text { Negative } & 50 \\ \text { Positive } & 4 \\ \text { Undetermined } & 4 \\ \text { Grade } & \\ \mathrm{G}_{1}-\mathrm{G}_{2} & 48 \\ \mathrm{G}_{3}-\mathrm{G}_{4} & 8 \\ \text { Not classified } & 2 \\ \mathrm{Chemotherapy} & \\ \mathrm{Yes}^{\mathrm{F}} & \\ \mathrm{FM}^{\mathrm{a}} & 19 \\ \mathrm{GP}^{\mathrm{a}} & 9 \\ \mathrm{No}^{\mathrm{b}} & 10 \\ \end{array}$

aFM, 5-Fu + MMC; GP, gemcitabine + platinumdrugs. 'Including patients not using any drug or not fully using drugs after surgery.

types of cancer tissue and cell lines, only a few studies focused on pancreatic cancer $(5,11,18,23)$. Even though high HIF- $1 \alpha$ expression has been detected in pancreatic cancer, its impact on the prognosis still remains uncertain. In this study, we investigated the expression of HIF-1 $\alpha$ and related proteins and their association to intratumoral microvessel density (IMD), apoptotic index (AI), Ki67 labeling index (Ki-67 LI) and other clinical features as well as their prognostic value in PDA.

\section{Materials and methods}

Patients. Fifty-eight patients with PDA who underwent radical surgery at our hospital between April 1993 and February 2005 were included in this study. Mean patient age was $60.66 \pm 11.02$ years. None of the patients had preoperative radiation or chemotherapy. Experienced pathologists provided detailed pathological diagnosis according to UICC TNM classification standards (4). Patient information and tumor characteristics are summarized in Table I. Normal pancreatic tissue was obtained from patients who underwent pancreatoduodenectomy or distal pancreatectomy for diseases other than pancreatic cancer. Anonymous use of leftover tumor material was part of standard treatment agreement with patients in our hospital. Patient survival data were obtained by telephone contact and direct home visit.

Immunohistochemistry. Formaldehyde-fixed and paraffinembedded cancer samples were retrieved from the archives of department of pathology. Normal pancreatic tissues were also fixed and paraffin-embedded. To reconfirm the diagnosis, our pathologists evaluated a representative hematoxylineosin stained slide from each patient before the following study. Tissue sections $(4 \mu \mathrm{m})$ were deparaffinized in xylene and rehydrated through graded ethanol. Slides were heated in $0.01 \mathrm{M}$ citrate buffer for $16 \mathrm{~min}$ in a microwave oven and cooled for $20 \mathrm{~min}$. Slides were washed in PBS and endogenous peroxidase was blocked (3\% hydrogen peroxide in methanol for $5 \mathrm{~min}$ ) and incubated in $10 \%$ normal goat serum for $30 \mathrm{~min}$. Sections were then incubated either with anti-HIF-1 $\alpha$ rabbit polyclonal antibody (BA0912, Wuhan Boster, China), mouse monoclonal antibody (QBEnd/10) against CD34 (M7165, Dako, Denmark) and mouse monoclonal antibody (Ki-S5) (M7187, Dako) at a dilution of 1:50, or with antiVEGF mouse monoclonal antibody (MAB-0243, Fuzhou Maixin Biotech Inc., China), anti-Glut-1 rabbit polyclonal antibody (RAB-526) and anti-survivin rabbit polyclonal antibody (RAB-0536) which were ready-to-use antibodies at room temperature for $60 \mathrm{~min}$. Visualization of binding antibodies was demonstrated by a two-step immunohistochemistry procedure using Supervision ${ }^{\mathrm{TM}}$ Universal (Anti-Mouse/ Rabbit) Detection Reagent (HRP) (D3004, Shanghai Changdao Biotech Co., Ltd., China) according to the manufacturer's instructions. Counter staining was performed with hematoxylin. For negative controls, the primary antibody was omitted and replaced by PBS.

TdT-mediated dUTP nick end labeling (TUNEL). TUNEL was done using in situ Cell Death Detection kit (Roche Diagnostic, Germany) as per directions. Briefly, deparaffinized sections were treated with proteinase $\mathrm{K}$ for $10 \mathrm{~min}$, followed by treatment with $0.3 \% \mathrm{H}_{2} \mathrm{O}_{2}$ in methanol $(10 \mathrm{~min})$, incubated with TUNEL reaction mixture $(60 \mathrm{~min})$ and peroxidaseconjugated antibody for $30 \mathrm{~min}$. Slides were then stained with diaminobenzidine solution for $10 \mathrm{~min}$ and counterstained with hematoxylin. Positive controls, sections were treated with DNase before TUNEL reaction mixture and the later was omitted in negative controls.

Semi-quantitative assessment of proteins and determination of AI and Ki67 LI. Results were evaluated independently by two investigators without prior knowledge of the patients' data. HIF- $1 \alpha$ expression was scored as,,-+++ and +++ , as described previously $(5,6)$. To determine VEGF and Glut-1 expression, percentage of positive cells and staining intensity points were added to produce a weighted score for each 

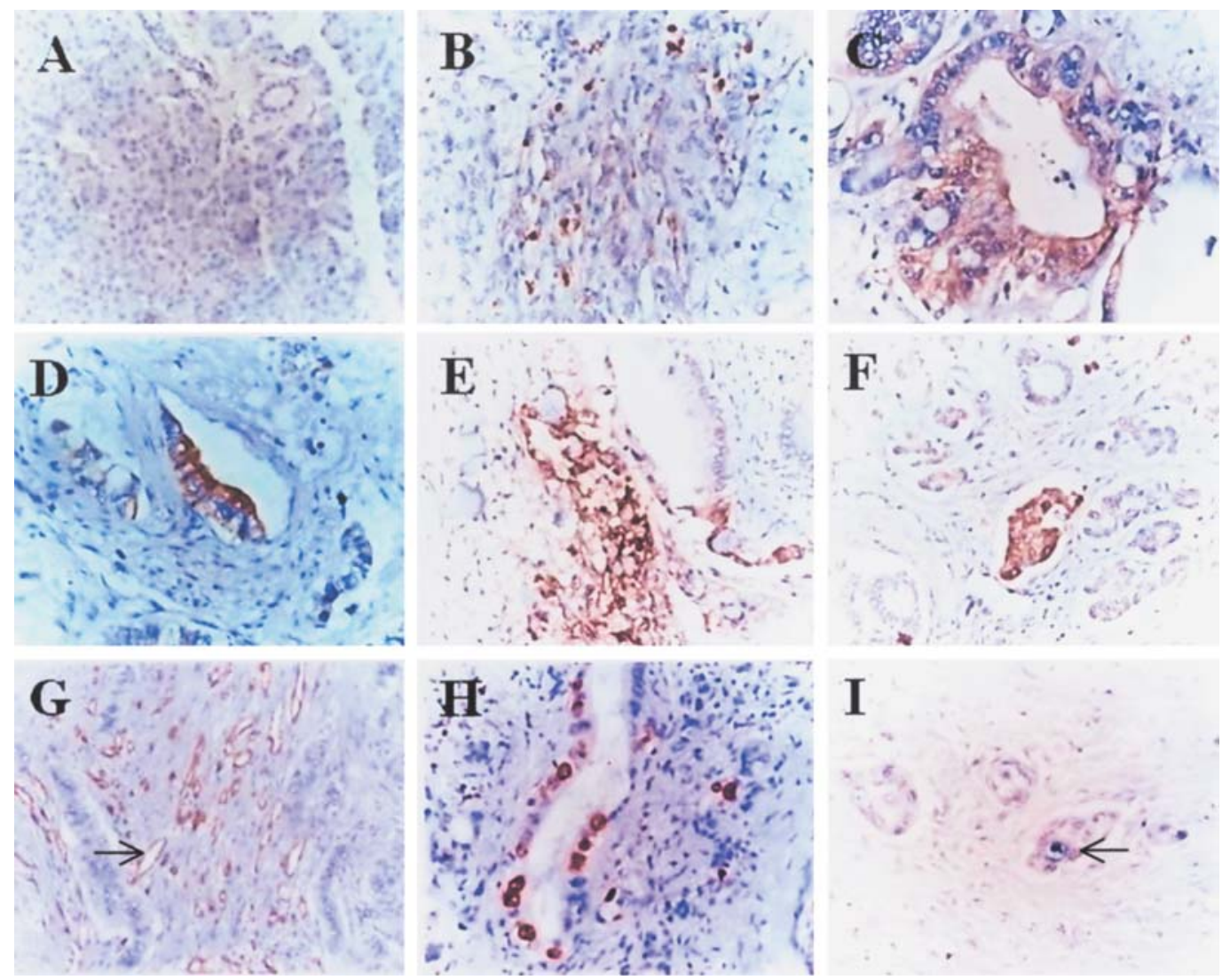

Figure 1. Demonstration of investigated proteins and apoptosis in normal and cancer pancreatic tissues by immunohistochemistry. (A) Negative expression of HIF-1 $\alpha$ in normal pancreatic tissue (x400). (B) Diffuse nucleus staining of HIF-1 $\alpha$ in malignant cells (x400). (C) Positivity of HIF-1 $\alpha$ in malignant cytoplasm (x400). (D) VEGF expression within cytoplasm and cell membrane of the cancerous cells (x400). (E) Cytoplasmic and cell membrane staining of Glut-1 in cancer cells (x400). (F) Positive survivin staining in the cytoplasm and nucleus of malignant cells (x400). (G) CD34 expression in vascular endothelial cells within the tumor (arrow shows one of the microvessels) (x200). (H) Ki-67 positivity in the nucleus of malignant ductal cells (x400). (I) A typical apoptotic cell (arrow) (x400).

case. The percentage of positive cells was rated as: 1 point, up to $10 \%$ positive cells; 2 points, $11-50 \%$ positive cells; 3 points, $51-80 \%$ positive cells; 4 points, $>81 \%$ positive cells. The staining intensity was classified as $0,1,2$ or 3 points for no staining, weak, moderate and strong intensity, respectively. Specimens were divided into four groups according to their weighted score:,$- 1-2$ points;,+ 3 points; ,$++ 4-5$ points and,$+++ 6-7$ points. For statistical reasons, tumors were classified into two groups: (-) and (+), low reactivity group, $(++)$ and $(+++)$, high reactivity group. Previous guidelines were adopted for the assessment of survivin expression and tumors were enrolled into negative (-) and positive $(+)$ categories $(7,8)$. IMD was assessed by light microscopy after immunostaining for CD34 as described $(9,10)$. For Ki-67 LI or AI calculation, prior scanning of the slides under low magnification (x100) was carried out to gain a general estimation of the staining status, followed by counting a minimum of 1000 total neoplastic cells under several consecutive high power fields $(\mathrm{x} 400)$ in the representative areas. Cells or bodies with questionable staining were discounted and necrotic areas were avoided for AI calculations.

When independent scoring of a case differed, it was rechecked, and the final weighted score was determined by recounting using a multi-headed microscope with the observers simultaneously viewing the slides. If the deviation was $<30 \%$ in continuous variable, the mean value was adopted as the final score, otherwise, the case was re-evaluated until a consensus was achieved.

Statistical analysis. The difference between groups of continuous data was identified by Student's t-test. Categorical variables were assessed by $\chi^{2}$ or Fisher's exact test. Spearman's rank correlation coefficient test was carried out for testing the association between ordinal variables. Univariate analysis of overall survival and survival curves were performed by Kaplan-Meier method, and the Cox proportional hazards model was used for multivariate analysis. A value of $\mathrm{P}<0.05$ was considered statistically significant. All analyses were performed with SPSS11.0.

\section{Results}

Expression of the investigated proteins. HIF-1 $\alpha$, VEGF, Glut-1 or survivin expression was not detected in the exocrine portion of all normal pancreatic samples (Fig. 1A). HIF-1 $\alpha$, VEGF, Glut-1 and survivin positive cells were detected in $41(70.7 \%)$, $45(77.6 \%), 39(67.2 \%)$ and $49(84.5 \%)$ out of 58 tumor blocks. HIF-1 $\alpha$ expression was present in a diffused pattern in the nucleus and/or cytoplasm of the tumor cells (Fig. 1B and $\mathrm{C}$ ). In addition, strong HIF-1 $\alpha$ expression was observed in cancer cells on the periphery of localized necrotic areas and in the cells around the borderline between tumor and adjacent 
Table II. Relationship between HIF-1 $\alpha$ and other investigated proteins in PDA.

\begin{tabular}{|c|c|c|c|c|c|c|}
\hline \multirow[b]{2}{*}{ Other protein expression } & \multicolumn{4}{|c|}{ HIF- $1 \alpha$ expression } & \multicolumn{2}{|c|}{ Spearman rank correlation } \\
\hline & $(-)(n=17)$ & $(+)(n=15)$ & $(++)(n=19)$ & $(+++)(n=7)$ & $\mathrm{r}$ & P-value \\
\hline \multicolumn{7}{|l|}{ VEGF } \\
\hline Negative $(n=13)$ & 7 & 4 & 2 & 0 & & \\
\hline Weak $(n=23)$ & 5 & 7 & 7 & 4 & & \\
\hline Moderate $(n=14)$ & 5 & 2 & 6 & 1 & & \\
\hline Strong $(n=8)$ & 0 & 2 & 4 & 2 & 0.334 & 0.010 \\
\hline \multicolumn{7}{|l|}{ Glut-1 } \\
\hline Negative $(n=19)$ & 8 & 9 & 1 & 1 & & \\
\hline Weak $(n=19)$ & 5 & 3 & 11 & 0 & & \\
\hline Moderate $(n=17)$ & 4 & 3 & 5 & 5 & & \\
\hline Strong $(n=3)$ & 0 & 0 & 2 & 1 & 0.423 & 0.001 \\
\hline \multicolumn{7}{|l|}{ Survivin } \\
\hline Negative $(n=9)$ & 4 & 2 & 2 & 1 & & \\
\hline Positive $(n=49)$ & 13 & 13 & 17 & 6 & 0.120 & 0.369 \\
\hline
\end{tabular}
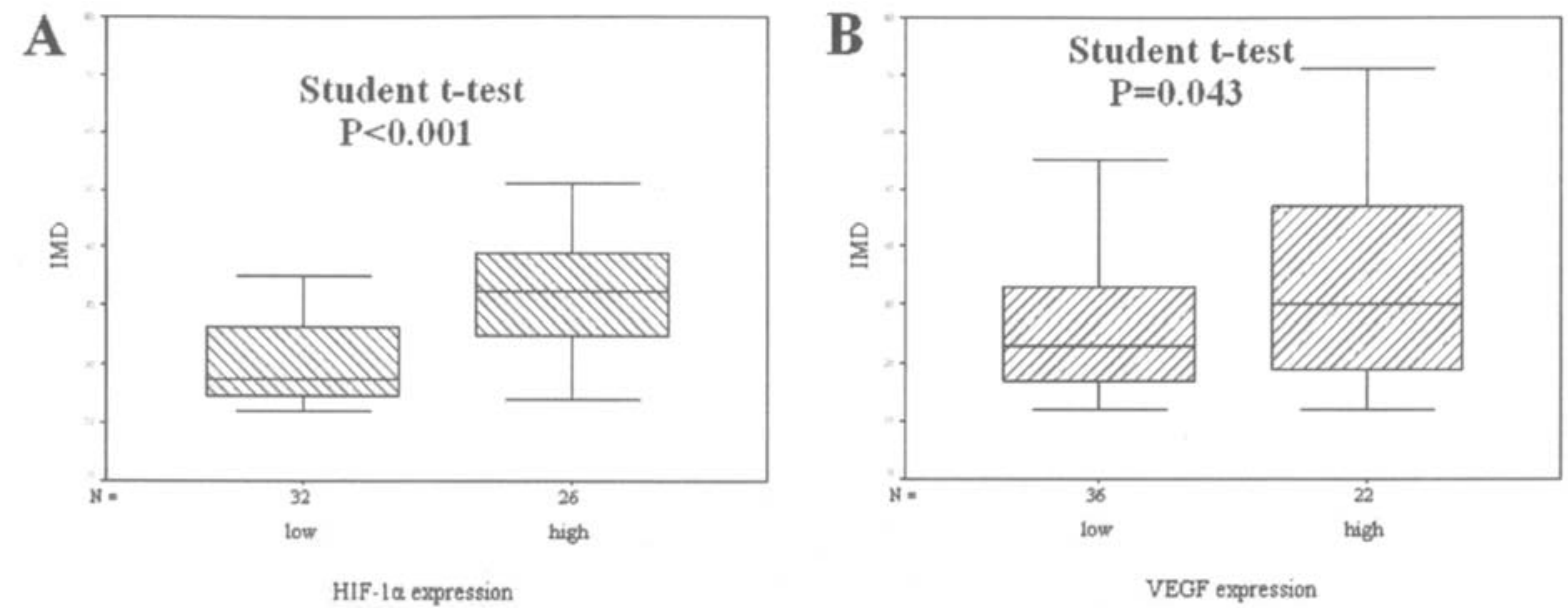

Figure 2. Boxplots of IMD of 58 specimens with PDA stratified for different levels of HIF-1 $\alpha$ and VEGF expression. (A) High levels of HIF-1 $\alpha$ expression significantly correlated with increased IMD (Student's t-test, $\mathrm{P}<0.001$ ). (B) Intensified expression of VEGF promoted tumor neoangiogenesis in PDA (Student's t-test, $\mathrm{P}=0.043$ ).

normal tissue. Negative (-), weak $(+)$, moderate $(++)$ and strong $(+++)$ expression staining categories were detected in the 17, 15, 19 and 7 cases, respectively. Staining for VEGF was mainly located within cytoplasm and cell membrane of the cancer cells (Fig. 1D) as negative (-), weak (+), moderate $(++)$ and strong (+++) in 13, 23, 14 and 8 cases, respectively. Glut-1, yellow-brown staining was visible in the cytoplasm and cell membrane of tumor cells (Fig. 1E). Distribution of Glut-1 staining was striking similar to HIF-1 $\alpha$ expression. There were 19, 19, 17 and 3 cases of tumor specimens showing negative $(-)$, weak $(+)$, moderate $(++)$ and strong (+++) Glut-1 expression. Of the studied specimens, 49 cases were positive for survivin staining in the cytoplasm or in the nucleus in some cases (Fig. 1F). Distinct microvessel frames for CD34 staining emerged under the light microscope (Fig. 1G). The mean IMD for the tumor group was 28.5 \pm 15.2 . Clear staining restricting to the nucleus indicated positive labeling for Ki-67 or interpreted cell apoptosis (Fig. 1H and I). The mean Ki-67 LI and AI of the cancer group were $28.27 \pm 14.49 \%$ and $1.48 \pm 0.83 \%$, respectively.

Relationship between HIF-1a and other associated proteins and IMD or indices. Spearman rank correlation revealed a significant positive linear correlation of HIF- $1 \alpha$ with VEGF $(\mathrm{r}=0.334 ; \mathrm{P}=0.010)$, and Glut-1 $(\mathrm{r}=0.423 ; \mathrm{P}=0.001)$ but not with survivin ( $\mathrm{r}=0.120 ; \mathrm{P}=0.369)$ (Table II). Expression of HIF-1 $\alpha$ $(\mathrm{P}<0.001)$ and VEGF $(\mathrm{P}=0.043)$ correlated positively with IMD (Fig. 2). AI inversely correlated with reactivity of HIF-1 $\alpha$ 
Table III. Correlation between HIF-1 $\alpha$ expression and mean AI and Ki-67 LI in pancreatic cancer.

\begin{tabular}{lccc}
\hline & \multicolumn{2}{c}{ HIF-1 $\alpha$ expression } & \multicolumn{2}{c}{ Student's t-test } \\
\cline { 2 - 4 } Indices $(\% \pm \mathrm{SD})$ & Low & High & P-value \\
\hline Mean AI & $1.77 \pm 0.77$ & $1.13 \pm 0.77$ & 0.003 \\
Mean Ki-67 LI & $25.04 \pm 13.61$ & $32.24 \pm 14.82$ & 0.056 \\
\hline
\end{tabular}

Table IV. Correlation between the expression of investigated proteins and clinicopathological data.

\begin{tabular}{|c|c|c|c|c|c|c|c|c|c|c|c|c|}
\hline \multirow[b]{2}{*}{ Parameters } & \multicolumn{3}{|c|}{ HIF- $1 \alpha$ expression } & \multicolumn{3}{|c|}{ VEGF expression } & \multicolumn{3}{|c|}{ Glut-1 expression } & \multicolumn{3}{|c|}{ Survivin expression } \\
\hline & Low & High & P-value & Low & High & P-value & Low & High & P-value & $(-)$ & $(+)$ & P-value \\
\hline \multicolumn{13}{|l|}{ Age (years) } \\
\hline$<60$ & 16 & 7 & & 15 & 8 & & 14 & 9 & & 4 & 19 & \\
\hline$\geq 60$ & 16 & 19 & $0.074^{\mathrm{a}}$ & 21 & 14 & $0.689^{\mathrm{a}}$ & 24 & 11 & $0.546^{\mathrm{a}}$ & 5 & 30 & $1.000^{\mathrm{b}}$ \\
\hline \multicolumn{13}{|l|}{ Gender } \\
\hline Male & 21 & 16 & & 21 & 16 & & 24 & 13 & & 5 & 32 & \\
\hline Female & 11 & 10 & $0.747^{\mathrm{a}}$ & 15 & 6 & $0.268^{\mathrm{a}}$ & 14 & 7 & $0.890^{\mathrm{a}}$ & 4 & 17 & $0.710^{\mathrm{b}}$ \\
\hline \multicolumn{13}{|l|}{ Tumor size } \\
\hline$<2 \mathrm{~cm}$ & 7 & 1 & & 7 & 1 & & 6 & 2 & & 2 & 6 & \\
\hline$\geq 2 \mathrm{~cm}$ & 25 & 25 & $0.063^{\mathrm{b}}$ & 29 & 21 & $0.139^{\mathrm{b}}$ & 32 & 18 & $0.701^{\mathrm{b}}$ & 7 & 43 & $0.597^{\mathrm{b}}$ \\
\hline \multicolumn{13}{|l|}{ LN status } \\
\hline Negative & 26 & 14 & & 30 & 10 & & 32 & 8 & & 7 & 33 & \\
\hline Positive & 6 & 12 & $0.025^{\mathrm{a}}$ & 6 & 12 & $0.002^{\mathrm{a}}$ & 6 & 12 & $0.001^{\mathrm{a}}$ & 2 & 16 & $0.706^{\mathrm{b}}$ \\
\hline \multicolumn{13}{|l|}{ TNM stage } \\
\hline I + II & 26 & 10 & & 29 & 7 & & 29 & 7 & & 7 & 29 & \\
\hline III + IV & 6 & 16 & $0.001^{\mathrm{a}}$ & 7 & 15 & $<0.001^{\mathrm{a}}$ & 9 & 13 & $0.002^{\mathrm{a}}$ & 2 & 20 & $0.459^{\mathrm{b}}$ \\
\hline \multicolumn{13}{|l|}{ Grade } \\
\hline $\mathrm{G}_{1}+\mathrm{G}_{2}$ & 28 & 20 & & 31 & 17 & & 32 & 16 & & 7 & 41 & \\
\hline $\mathrm{G}_{3}+\mathrm{G}_{4}$ & 3 & 5 & $0.445^{\mathrm{b}}$ & 3 & 5 & $0.241^{\mathrm{b}}$ & 4 & 4 & $0.437^{\mathrm{b}}$ & 1 & 7 & $1.000^{\mathrm{b}}$ \\
\hline
\end{tabular}

${ }^{\mathrm{a}} \chi^{2}$ test; ${ }^{b}$ Fisher's exact test.

staining $(\mathrm{P}=0.003)$. Increased Ki-67 LI was accompanied by high levels of HIF-1 $\alpha$ expression $(\mathrm{P}=0.056)$ (Table III).

Expression of the studied proteins in relation to clinicopathological parameters. As shown in Table IV, tumors with high HIF-1 $\alpha$ expression were larger than those with low HIF-1 $\alpha$ expression (Fisher's exact test, $\mathrm{P}=0.063$ ). Besides, high levels of HIF-1 $\alpha$ expression, as well as VEGF and Glut- 1 expression, significantly correlated with advanced tumor stage (III + IV) and lymph node metastasis.

Survival analysis. Overall survival was defined as the period from the day of surgery until death of the patient. Death from a cause other than cancer relapse or survival until the end of observation period was considered a censoring event.
Follow-up data were available for 53 patients, however, we lost track of 5 patients during the observation period. The median follow-up time was 13.0 months and the survival rate was $50.4 \%$ and $26.0 \%$ at 1 and 2 years. Thirty-eight patients died of pancreatic cancer at the endpoint of observation period while only one patient was still alive at 5 years following the operation. As shown in Table V and Fig. 3, univariate analysis revealed that higher expression of HIF-1 $\alpha$, VEGF and Glut-1 were respectively correlated with poor prognosis. Survivin expression was not a prognostic factor for overall survival. IMD and AI appeared to have a marginal significance on prognosis, whereas Ki-67 LI had no prognostic value. In addition, we evaluated the impact of clinicopathological features and chemo-therapy applied after surgery on overall survival. As a result, low histological 
Table V. Univariate and multivariate analysis of overall survival of 58 patients with PDA.

\begin{tabular}{|c|c|c|c|c|}
\hline \multirow[b]{2}{*}{ Variables } & \multirow{2}{*}{$\frac{\text { Univariate analysis }}{\text { P-value }}$} & \multicolumn{3}{|c|}{ Multivariate analysis } \\
\hline & & P-value & Relative risk & $95 \% \mathrm{CI}$ \\
\hline Age ( $<60$ years vs $\geq 60$ years) & 0.3395 & & & \\
\hline Gender (male vs. female) & 0.5932 & & & \\
\hline Histological grade $\left(G_{1}+G_{2}\right.$ vs. $\left.G_{3}+G_{4}\right)$ & 0.0118 & 0.991 & & \\
\hline Lymph node status (positive vs. negative) & $<0.0001$ & 0.700 & & \\
\hline TNM stage (I + II vs. III + IV) & $<0.0001$ & 0.235 & & \\
\hline Margin status (positive vs. negative) & 0.1352 & & & \\
\hline Chemotherapy (yes vs. no) & 0.3814 & & & \\
\hline FM vs. GPa & 0.4565 & & & \\
\hline IMD ( $<$ mean vs. $\geq$ mean $)$ & 0.0835 & & & \\
\hline $\mathrm{AI}(<$ mean vs. $\geq$ mean $)$ & 0.0777 & & & \\
\hline Ki-67 LI (< mean vs. $\geq$ mean) & 0.5782 & & & \\
\hline HIF-1 $\alpha$ (high vs. low) & 0.0208 & 0.051 & 2.220 & $0.997-4.994$ \\
\hline VEGF (high vs. low) & 0.0002 & 0.014 & 2.603 & $1.210-5.599$ \\
\hline Glut-1 (high vs. low) & 0.0088 & 0.161 & & \\
\hline Survivin (positive vs. negative) & 0.6614 & & & \\
\hline
\end{tabular}

${ }^{\mathrm{a}} \mathrm{FM}, 5-\mathrm{Fu}+\mathrm{MMC} ; \mathrm{GP}$, gemcitabine + platinum drugs.
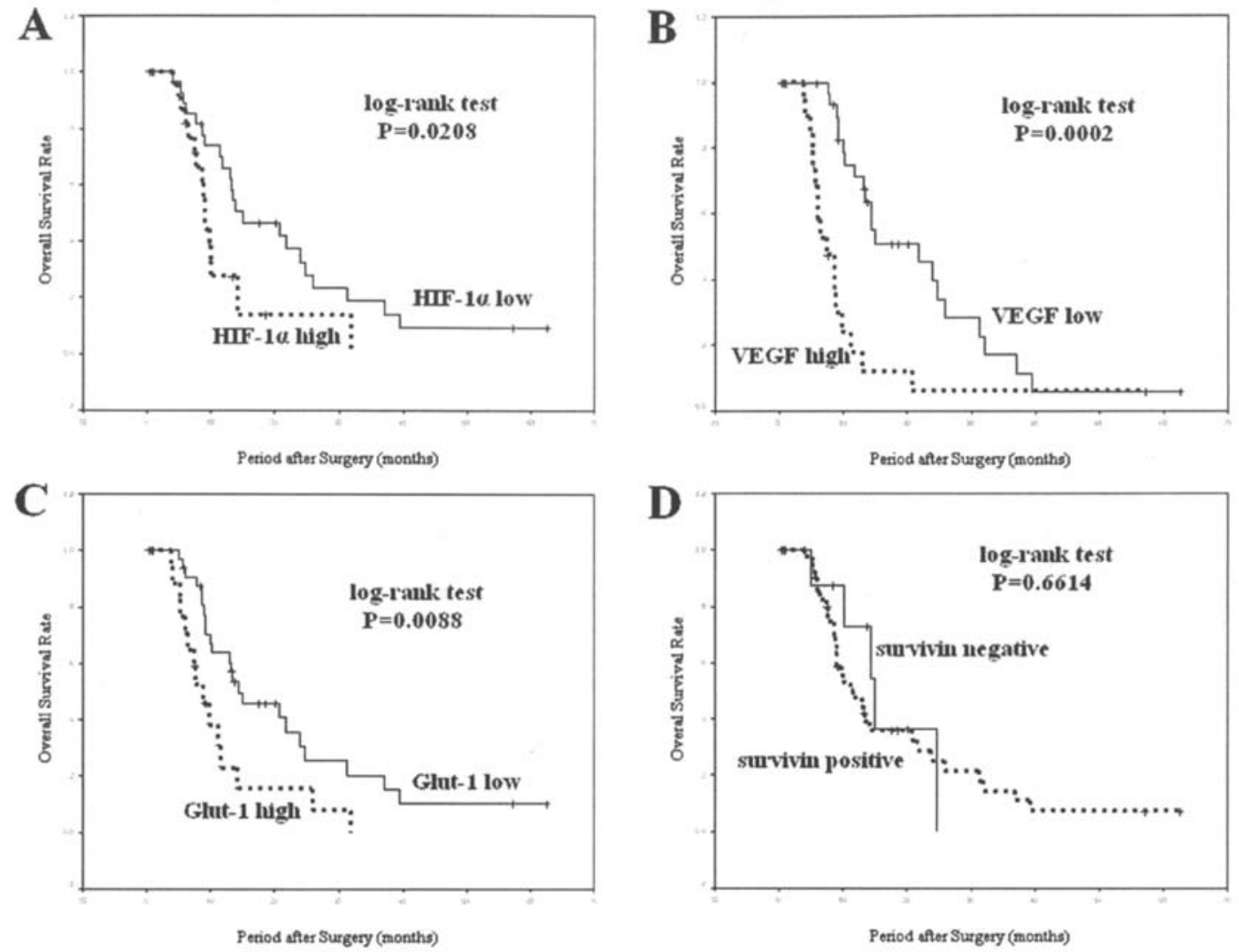

Figure 3. Survival curves of the PDA patients with regard to HIF-1 $\alpha$ (A), VEGF (B), Glut-1 (C) and survivin (D) expression. (A) PDA patients with low HIF-1 $\alpha$ expression survived longer than HIF-1 $\alpha$ high group $(\mathrm{P}=0.0208$ ). (B) High expression of VEGF indicates a shorter overall survival for patients with PDA $(\mathrm{P}=0.0002)$. (C) The overall survival rate of patients with high Glut-1 expression tumors was significantly lower than that of patients with low Glut-1 expression tumors. (D) Survivin expression does not influence the overall survival rate of PDA patients ( $\mathrm{P}=0.6614)$.

grade, present of lymph node metastasis and advanced TNM stage significantly predicted patients' survival, whereas age, gender, margin status and adjuvant chemotherapy had no predictive value. All factors that were significant for 
predicting overall survival by univariate analysis were included in the multivariate Cox regression analysis, which revealed that HIF-1 $\alpha$ expression was a survival predictor of borderline significance and VEGF maintained its independence for prognosis.

\section{Discussion}

The present study demonstrated that $70.7 \%$ of the investigated PDA samples showed positive HIF- $1 \alpha$ staining, consistent with previous reports $(5,11)$. We have observed two patterns of HIF-1 $\alpha$ expression representative of two distinct mechanisms of induction (12). Focal strong HIF-1 $\alpha$ expression in the tumor cells around necrosis and invading margins indicated its induction by hypoxia while the diffused nuclear and/or cytoplasm staining suggested an oxygenindependent pathway. High levels of HIF-1 $\alpha$ expression, regardless of expression pattern, indicated lymph node metastasis and a tendency of larger tumor size as well as advanced TNM stage. To determine whether this group of patients had similar characteristics to larger patient group with pancreatic cancer, we analyzed the relationship between clinical outcome and the established prognostic factors. Expectedly, advanced tumor stage, histological grade and lymph node metastasis were confirmed to be adverse prognostic factors. Furthermore, we analyzed the prognostic value of HIF- $1 \alpha$ which turned out to be of statistical significance. Therefore, this suggests that HIF-1 $\alpha$ promotes aggressive behavior of PDA, encouraging us to continue implementing our investigation in detail.

Previous studies have shown that HIF-1 $\alpha$ expression closely correlates with VEGF in several kinds of human cancers $(9,11,13-17)$. Buchler et al demonstrated that hypoxia induced HIF- $1 \alpha$ dramatically transactivated VEGF gene expression in pancreatic cancer cells in vitro and explored colocalization of VEGF mRNA and HIF- $1 \alpha$ protein in the same ductal cancer cells (18). The present study shows that elevated HIF-1 $\alpha$ expression correlated significantly with intense VEGF expression, which suggested that HIF-1 $\alpha$ may up-regulate VEGF expression. VEGF is the most potent proangiogenic factor known to directly participate in angiogenesis (19). Therefore, intensified VEGF expression might be responsible for increased IMD. Our results showed that HIF- $1 \alpha$ and VEGF were positively correlated with IMD, as shown by others in pancreatic cancer $(5,11)$, gastric cancer (14), bladder cancer (15), hepatocellular carcinoma (16) and colorectal adenocarcinoma $(9,17)$. IMD is generally recognized as a predictor of poor prognosis of pancreatic carcinomas $(20,21)$. However, in the present study, IMD was marginally significant for predicting survival, whereas high levels of HIF- $1 \alpha$ and VEGF were significantly associated with worse clinical outcome. These findings suggested that the role played by HIF-1 $\alpha$ could not be solely elucidated by angiogenesis via up-regulation of VEGF. Therefore, we further investigated several vital HIF-1 related genes to gain a more comprehensive view of PDA.

Younes et al found that Glut-1 is undetectable in normal pancreatic tissue, but widely expressed in pancreatic adenocarcimoma, and hypothesized that Glut-1 expression promotes utilization of energy in tumor cells, contributing to their aggressive behavior (22). Akakura et al reported that constitutive expression of HIF- $1 \alpha$ made pancreatic cancer cells survive and proliferate under severe hypoxia and nutrient deprivation partially through up-regulation of Glut-1 gene (23). In the present study, we demonstrated that $39 / 58$ (67.2\%) PDA cases were positive for Glut-1 and its expression highly correlated with HIF-1 $\alpha$. In addition, the expression pattern of Glut-1 is strikingly similar to HIF-1 $\alpha$. Collectively, these results indicate that HIF- $1 \alpha$ is a Glut- 1 stimulator in the complex tumor microenvironment. In order to determine whether up-regulated Glut-1 had influence on patients or not, we further investigated its correlation with clinicopathological parameters as well as its impact on prognosis. As expected, we found that high expression of Glut-1 always predicted late tumor stage and lymph node metastasis and unfavorable clinical outcome. To our knowledge, ours is the first study to evaluate the effect of Glut-1 expression on pancreatic cancer in vivo. Although, a relationship between Glut-1 expression and the clinical factors in other human cancers is controversial, it is generally agreed that Glut-1 expression forecast a dismal prognosis $(24,25)$.

Survivin, a recently identified novel anti-apoptosis gene, is a member of the IAPs family widely expressed in human cancers including PDA but not in most normal adult tissues (26). Several studies have reported that survivin is over expressed in pancreatic cancers (7,27-30), and plays an important role in carcinogenesis of pancreas through its antiapoptotic effects $(30,31)$. However, whether survivin gene is a survival predictor for patients with pancreatic cancer remains controversial. Kami et al first reported that survivin expression may be a prognostic factor in pancreatic cancers (29). Whereas Lee et al failed to find similar results due to limitation of patients and improper proportion of survivinnegative patients for comparison (27). Likewise, in the present study, since only nine patients were survivin negative, no relationship between survivin and clinicopathological features with the exception of AI was detected (data not shown). Therefore, it is suggested that survivin may not be useful in predicting survival and further studies with large number of patients are required to determine the clinical significance of survivin in pancreatic cancer. Moreover, we did not find a surmised relationship between survivin and HIF-1 $\alpha$ expression. Wei et al showed that the expression of HIF-1 $\alpha$ mRNA correlated closely with survivin expression (32). Chang et al have recently shown that down regulation of HIF-1 $\alpha$ caused reduction in survivin expression in pancreatic cancer cell line transfected with antisense HIF-1 $\alpha$ plamid in vitro (33). However, these results can be explained as follows: first, the expression of HIF- $1 \alpha$ protein is influenced not only by increased mRNA levels but also by oxygen tension at posttranscriptional level; second, artificial hypoxia environment in vitro could not comprehensively mimic the actual anoxia inside solid tumors.

Cell proliferation and apoptosis are two fundamental aspects of tumor progression and their conjunct influence determines the clinical outcome of cancer patients. Present results demonstrated that strong expression of HIF- $1 \alpha$ $(\mathrm{P}=0.056)$ and VEGF (data not shown), is associated with enhanced Ki-67 expression. Additionally, increased Glut-1 expression significantly correlated with increased Ki-67 LI 
in tumors (data not shown). Thus, it can be deduced that HIF-1 $\alpha$ via up-regulation of its downstream genes such as VEGF and Glut-1, that provide energy and oxygen, may induce pancreatic cell proliferation. On the other hand, we revealed that HIF-1 $\alpha$ expression adversely correlated with AI in PDAs. Akakura et al, consistent with our results, reported that pancreatic cell lines with high concentration of constitutively expressed HIF-1 $\alpha$ under normoxia were resistant to apoptosis induced by hypoxia and glucose deprivation (23). Chen et al demonstrated that dominant negative HIF-1 $\alpha$ rendered pancreatic cancer cells sensitive to apoptosis and growth inhibition by hypoxia and energy shortage (34). However, as we know, since HIF-1 $\alpha$ can manipulate cell apoptosis, it is likely that certain factors may be able to determine whether HIF-1 can shift the balance towards apoptosis or resistance $(35,36)$. Kitada et al recently reported that no relationship had been found between HIF-1 $\alpha$ and apoptotic index in pancreatic adeno-carcinoma (5), which may be attributed to different degrees of tumor hypoxia between groups and varied stratifying criteria for HIF-1 $\alpha$. Since we observed no relationship between HIF-1 $\alpha$ and survivin, we hypothesized that anti-apoptotic function of HIF-1 $\alpha$ may be enhanced by some other mechanisms, e.g. p53 gene mutation.

To date, validity of HIF- $1 \alpha$ as an independent prognostic factor in diverse human cancers is controversial. Different patterns of HIF- $1 \alpha$ expression have been reported to have differential prognostic impact on breast cancer (37). Moreover, HIF-1 $\alpha$ expression during different stages of breast cancer has differential power on survival prediction $(38,39)$. In addition, since few studies have been focused on evaluating prognostic value of HIF-1 $\alpha$ in PDA patients, therefore, we enrolled HIF-1 $\alpha$, associated proteins and clinical features that were proved to be significant by log-rank test in Cox regression. Results show that HIF- $1 \alpha$ has an association of borderline significance with decreased overall survival and VEGF is an independent prognostic factor for unfavorable prognosis.

In conclusion, our data show that HIF-1 $\alpha$, VEGF and Glut-1 proteins are over-expressed in PDAs, that by promoting angiogenesis and proliferation and inhibiting apoptosis, they accelerate the pace of tumor development towards malignant phenotype. Moreover, HIF- $1 \alpha$ and VEGF were confirmed to be potential predictors of poor prognosis. Therefore, it is suggested that PDA patients may substantially benefit from treatments targeting HIF- $1 \alpha$, and a routine evaluation of these proteins by immunohistochemistry may improve our insight into enhanced treatment after surgery.

\section{Acknowledgements}

This study was supported by our hospital and Board of Health Fund for Scientific Research of Shanghai (no. 024012), China. The authors thank Dr Jia-Wei Chen and Zhao-Rui Yang for their technical assistance.

\section{References}

1. Kallio PJ, Wilson WJ, O'Brien S, Markino Y and Poellinger L: Regulation of the hypoxia-inducible transcription factor lalpha by the ubiquitin-proteasome pathway. J Biol Chem 274: 6519-6525, 1999.
2. Zhong H, Chiles K, Feldser D, et al: Modulation of hypoxiainducible factor 1alpha expression by the epidermal growth factor/phosphatidylinositol 3-kinase/PTEN/AKT/FRAP pathway in human prostate cancer cells: implications for tumor angiogenesis and therapeutics. Cancer Res 60: 1541-1545, 2000.

3. Talar-Wojnarowska R and Malecka-Panas E: Molecular pathogenesis of pancreatic adenocarcinoma: potential clinical implications. Med Sci Monit 12: 186-193, 2006.

4. International Union Against Cancer (UICC): Pancreas. In: TNM Classification of Malignant Tumors. Sobin LH and Wittekind C (eds). 5th edition. John Wiley \& Sons, Inc., New York, pp87-90, 1997.

5. Kitada T, Seki S, Sakaguchi H, Sawada T, Hirakawa K and Wakasa K: Clinicopathological significance of hypoxia-inducible factor-1alpha expression in human pancreatic carcinoma. Histopathology 43: 550-555, 2003

6. Zhong H, De Marzo AM, Laughner E, et al: Over-expression of hypoxia-inducible factor 1alpha in common human cancers and their metastases. Cancer Res 59: 5830-5835, 1999.

7. Sarela AI, Verbeke CS, Ramsdale J, Davies CL, Markham AF and Guillou PJ: Expression of survivin, a novel inhibitor of apoptosis and cell cycle regulatory protein in pancreatic cancer. Br J Cancer 86: 886-892, 2002.

8. Tanaka K, Iwamoto S, Gon G, Nohara T, Iwamoto M and Tanigawa N: Expression of survivin and its relationship to loss of apoptosis in breast carcinoma. Clin Cancer Res 6: 127-134, 2000.

9. Kuwai T, Kitadai Y, Tanaka S, et al: Expression of hypoxiainducible factor-1 alpha is associated with tumor vascularizaion in human colorectal carcinoma. Int J Cancer 105: 176-181, 2003

10. Theodoropoulos VE, Lazaris AC, Kastriotis I, et al: Evaluation of hypoxia-inducible factor-1 alpha overexpression as a predictor of tumor recurrence and progression in superficial urothelial bladder carcinoma. BJU Int 95: 425-431, 2005.

11. Shibaji T, Nagao M, Ikeda N, et al: Prognostic significance of HIF-1 alpha overexpression in human pancreatic cancer. Anticancer Res 23: 4721-4727, 2003.

12. Chun YS, Kim MS and Park JW: Oxygen-dependent and independent regulation of HIF-1alpha. J Korean Med Sci 17 581-588, 2002.

13. Urano N, Fujiwara Y, Doki Y, et al: Overexpression of hypoxiainducible factor- 1 alpha in gastric adenocarcinoma. Gastric Cancer 9: 44-49, 2006.

14. Mizokami K, Kakeji Y, Oda S, et al: Clinicopathologic significance of hypoxia-inducible factor 1alpha overexpression in gastric carcinomas. J Surg Oncol 94: 149-154, 2006.

15. Theodoropoulos VE, Lazaris AC, Sofras F, et al: Hypoxiainducible factor 1alpha expression correlates with angiogenesis and unfavorable prognosis in bladder cancer. Eur Urol 46: 200-208, 2004.

16. Huang GW, Yang LY and Lu WQ: Expression of hypoxiainducible factor 1alpha and vascular endothelial growth factor in hepatocellular carcinoma: impact on neovascularization and survival. World J Gastroenterol 11: 1705-1708, 2005.

17. Jiang CQ, Fan LF, Liu ZS, et al: Expression levels and significance of hypoxia inducible factor- 1 alpha and vascular endothelial growth factor in human colorectal adenocarcinoma Clin Med J 117: 1541-1546, 2004.

18. Buchler P, Reber HA, Buchler M, et al: Hypoxia-inducible factor 1 regulates vascular endothelial growth factor expression in human pancreatic cancer. Pancreas 26: 56-64, 2003.

19. Choi KS, Bae MK, Jeong JW, Moon HE and Kim KW: Hypoxiainduced angiogenesis during carcinogenesis. J Biochem Mol Biol 36: 120-127, 2003

20. Ikeda N, Adachi M, Taki T, et al: Prognostic significance of angiogenesis in human pancreatic cancer. Br J Cancer 79: 1553-1563, 1999.

21. Linder S, Blasjo M, von Rosen A, Parrado C, Falkmer UG and Falkmer S: Pattern of distribution and prognostic value of angiogenesis in pancreatic duct carcinoma: a semiquantitative immunohistochemical study of 45 patients. Pancreas 22: 240-247, 2001.

22. Younes M, Lechago LV, Somoano JR, Mossharaf M and Lechago J: Wide expression of the human erythrocyte glucose transporter Glut1 in human cancers. Cancer Res 56: 1164-1167, 1996.

23. Akakura N, Kobayashi M, Horiuchi I, et al: Constitutive expression of hypoxia-inducible factor-1alpha renders pancreatic cancer cells resistant to apoptosis induced by hypoxia and nutrient deprivation. Cancer Res 61: 6548-6554, 2001. 
24. Cooper R, Sarioglu S, Sokmen S, et al: Glucose transporter-1 (Glut-1): a potential marker of prognosis in rectal carcinoma. $\mathrm{Br}$ J Cancer 89: 870-876, 2003.

25. Haber RS, Rathan A, Weiser KR, et al: Glut-1 glucose transporter expression in colorectal carcinoma: a marker for poor prognosis. Cancer 83: 34-40, 1998.

26. Ambrosini G, Adida C and Altieri DC: A novel anti-apoptosis gene, survivin, expressed in cancer and lymphoma. Nat Med 3: 917-921, 1997.

27. Lee MA, Park GS, Lee HJ, et al: Survivin expression and its clinical significance in pancreatic cancer. BMC Cancer 5: 127, 2005.

28. Qiao JG, Zhang YQ, Yin YC and Tan Z: Expression of survivin in pancreatic cancer and its correlation to expression of Bcl-2. World J Gastroenterol 10: 2759-2761, 2004.

29. Kami K, Doi R, Koizumi M, et al: Survivin expression is a prognostic marker in pancreatic cancer patients. Surgery 136: 443-448, 2004.

30. Satoh K, Kaneko K, Hirota M, Masamune A, Satoh A and Shimosegawa T: Expression of survivin is correlated with cancer cell apoptosis and is involved in the development of human pancreatic duct cell tumors. Cancer 92: 271-278, 2001.

31. Bhanot U, Heydrich R, Moller P and Hasel C: Survivin expression in pancreatic intraepithelial neoplasia (PanIN): steady increase along the developmental stages of pancreatic ductal adenocarcinoma. Am J Surg Pathol 30: 754-759, 2006.

32. Wei H, Wang $\mathrm{C}$ and Chen L: Proliferating cell nuclear antigen, survivin, and CD34 expressions in pancreatic cancer and their correlation with hypoxia-inducible factor 1alpha. Pancreas 32: $159-163,2006$
33. Chang Q, Qin R, Huang T, Gao J and Feng Y: Effect of antisense hypoxia-inducible factor 1 alpha on progression, metastasis, and chemosensitivity of pancreatic cancer. Pancreas 32: 297-305, 2006.

34. Chen J, Zhao S, Nakada K, et al: Dominant-negative hypoxiainducible factor-1 alpha reduces tumorigenicity of pancreatic cancer cells through the suppression of glucose metabolism. Am J Pathol 162: 1283-1291, 2003

35. Greijer AE and van der Wall E: The role of hypoxia inducible factor 1 (HIF-1) in hypoxia induced apoptosis. J Clin Pathol 57: 1009-1014, 2004

36. Piret JP, Mottet D, Raes M and Michiels C: Is HIF-1alpha a proor an anti-apoptotic protein? Biochem Parmacol 64: 889-892 2002.

37. Vleugel MM, Greijer AE, Shvarts A, et al: Differential prognostic impact of hypoxia induced and diffuse HIF-1alpha expression in invasive breast cancer. J Clin Pathol 58: 172-177, 2005.

38. Bos R, van der Groep P, Greijer AE, et al: Levels of hypoxiainducible factor-1alpha independently predict prognosis in patients with lymph node negative breast carcinoma. Cancer 97: 1573-1581, 2003.

39. Schindl M, Schoppmann SF, Samonigg H, et al: Overexpression of hypoxia-inducible factor 1alpha is associated with an unfavorable prognosis in lymph node-positive breast cancer. Clin Cancer Res 8: 1831-1837, 2002. 